\title{
Isolation of a goose parvovirus from swan and its molecular characteristics
}

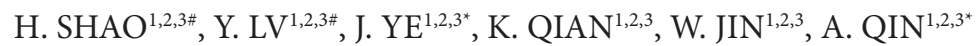

\begin{abstract}
${ }^{1}$ Ministry of Education Key Lab for Avian Preventive Medicine, Yangzhou University, No.12 East Wenhui Road, Yangzhou, Jiangsu, 225009, P. R.China; ${ }^{2}$ Key Laboratory of Jiangsu Preventive Veterinary Medicine, Yangzhou University, Yangzhou, 225009, P. R. China; ${ }^{3}$ Tiangsu Coinnovation Center for Prevention and Control of Important Animal Infectious Diseases and Zoonoses, Yangzhou, 225009, P. R. China
\end{abstract}

Summary. - Goose parvovirus (GPV) causes high mortality and morbidity in goslings and Muscovy ducklings. In this study, a GPV was isolated from a 20-day old swan in Shanghai, China. Complete genome of the swan isolate contained 5,050 nt and showed the highest homology with Taiwanese GPV isolates from 1982. In comparison with the Chinese mainland GPV isolates reported previously, the swan isolate shows two deletions, particularly at positions $67-80$ and 334-347 in inverted terminal repeats (ITRs). These findings suggest that the swan could serve as a potential host for GPV and provide insights into molecular characteristics and etiology of GPV.

Keywords: swan; goose parvovirus; isolation; genome; molecular characteristics

\section{Introduction}

Goose parvovirus (GPV) is assigned to the Parvoviridae family, the Parvovirinae subfamily and the Dependovirus genus, respectively. GPV was first documented by Fang in 1962 and the virus causes highly contagious and fatal disease in goslings and Muscovy ducklings (Fang, 1962; Gough et al., 2005; Lu et al., 1993; Takehara et al., 1995; Zadori et al., 1995). GPV has a linear single stranded DNA genome of approximately 5,106 nt (Brown et al., 1995; Zadori et al., 1995). The genome of GPV contains two ORFs flanked by inverted terminal repeat (ITR) regions (Zadori et al., 1995). The first ORF encodes the non-structural protein (NS), and the second ORF encodes the capsid proteins VP1-3 (Zadori et al., 1995). Current GPV distribution is wide (Derzsy et al., 1970; Irvine et al., 2008; Jansson et al., 2007; Lu et al., 1993; Schettler, 1971; Sirivan et al., 1998; Takehara et al., 1995; Wan, et al., 2011; Wozniakowski et al., 2009). GPV is mainly isolated

*Corresponding authors. E-mail: aijian@yzu.edu.cn or jqye@yzu. edu.cn; phone:+86-0514-87979217. "These authors contributed equally to this work.

Abbreviations: GPV = goose parvovirus; ITR = invert terminal repeat; $\mathrm{VP} 1=$ viral protein 1 ; NS = non-structual protein from goslings and Muscovy ducklings, but only seven GPV whole genome sequences are available in GenBank. In this study, a GPV was isolated from swan in Shanghai, China and its complete genome was sequenced and analyzed.

\section{Materials and Methods}

Virus isolation. A 20-day-old sick swan from a national zoo in Shanghai was suspected with GPV infection based upon clinical signs and gross pathology of severe intestinal obstruction. The viral isolation was performed by inoculating the supernatant of the liver and intestinal homogenates obtained from the swan into 12-day-old goose embryonated eggs. Briefly, the liver and intestine from the swan were first homogenized in PBS. After freezing and thawing three times, the homogenates were treated with streptomycin $(1000 \mu \mathrm{g} /$ $\mathrm{ml})$ and penicillin $(1000 \mathrm{U} / \mathrm{ml})$ at $37^{\circ} \mathrm{C}$ for $30 \mathrm{~min}$. After centrifugation at $10,000 \mathrm{rpm}$ for $20 \mathrm{~min}$, the supernatants of the homogenates were inoculated into 12-day-old goose embryonated egg. The inoculated eggs were kept in the incubator at $37^{\circ} \mathrm{C}$ for seven days.

DNA extraction. The viral DNA was prepared using phenol-chloroform method. Briefly, $437.5 \mu$ l of the egg allantoic 


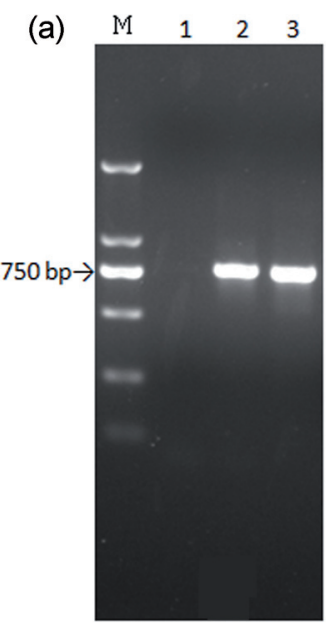

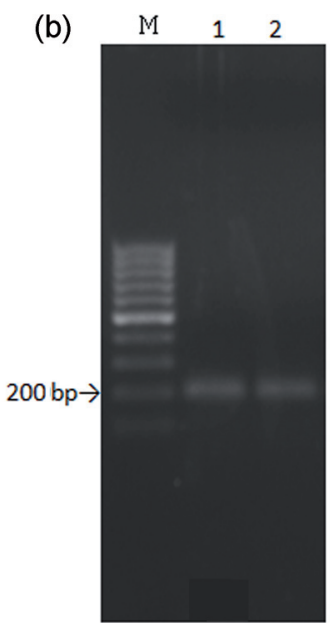

Fig. 1

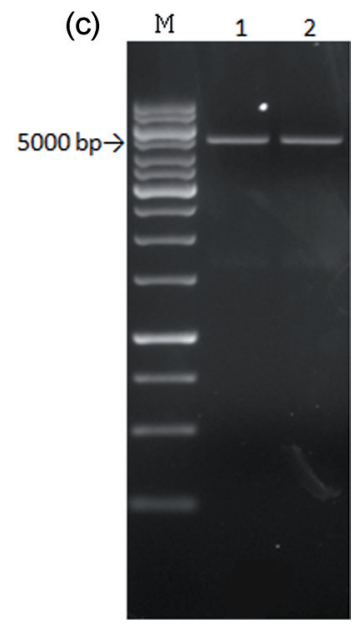

Identification of the swan GPV isolate by PCR

Products of PCR I (a), PCR II (b) and PCR III (c) were separated by PAGE. (a) Negative control (lane 1), liver (lane 2) and intestine (lane 3) of the infected swan and DL2000DNA Marker (lane M); (b) The swan GPV isolate with PCR II reaction (lanes 1 and 2) and 100 bp DNA Marker (lane M); (c) The swan GPV isolate with PCR III reaction (lanes 1 and 2) and $1 \mathrm{~kb}$ DNA Marker (lane M).

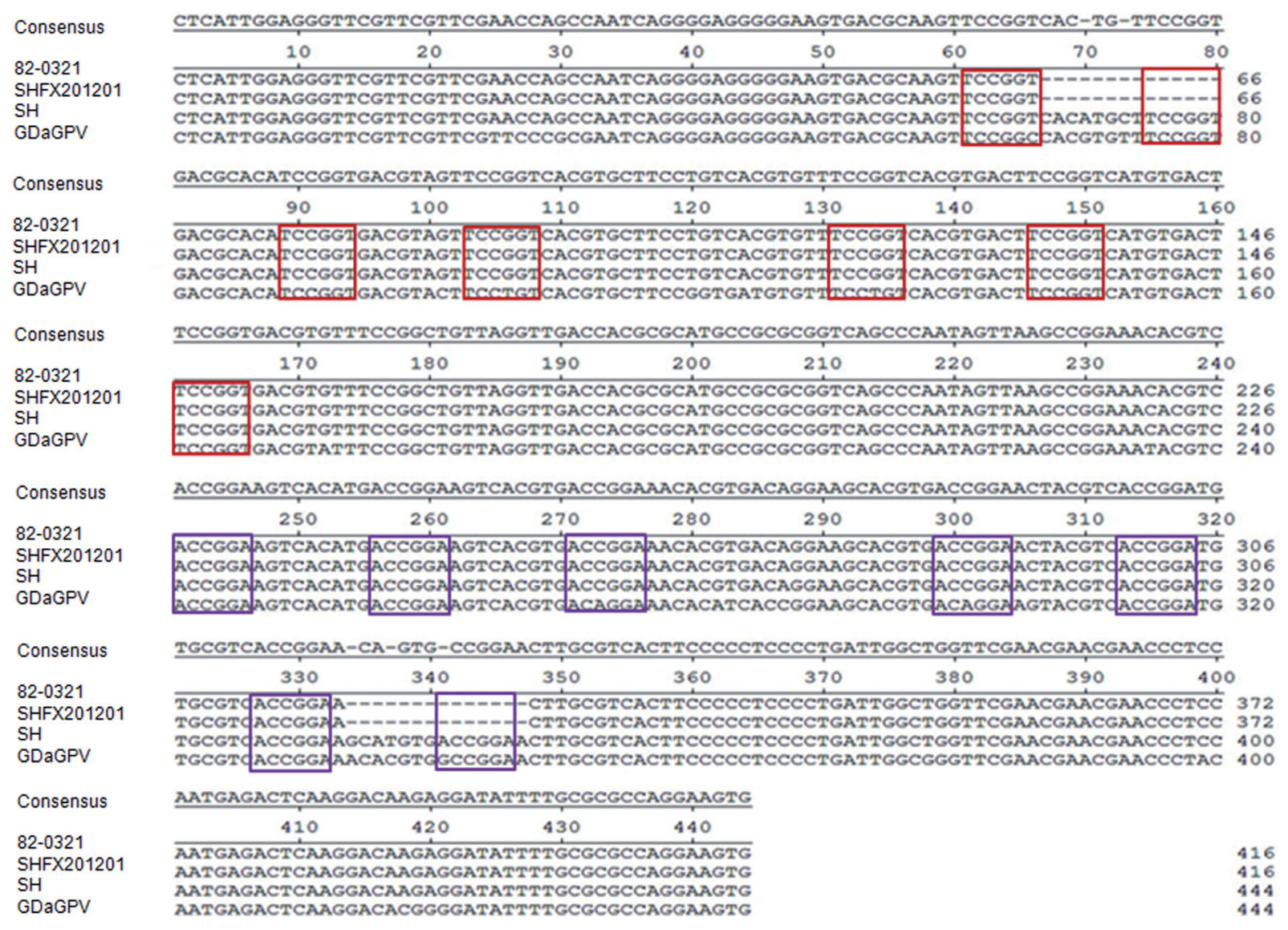

Fig. 2

Multiple alignment of ITR sequences of GPV isolates

The deletions at nt positions 67-80 and 334-347 are shown as dashed lines. The sequences TCCGGT and ACCGGA are shown in red and purple squares, respectively. 

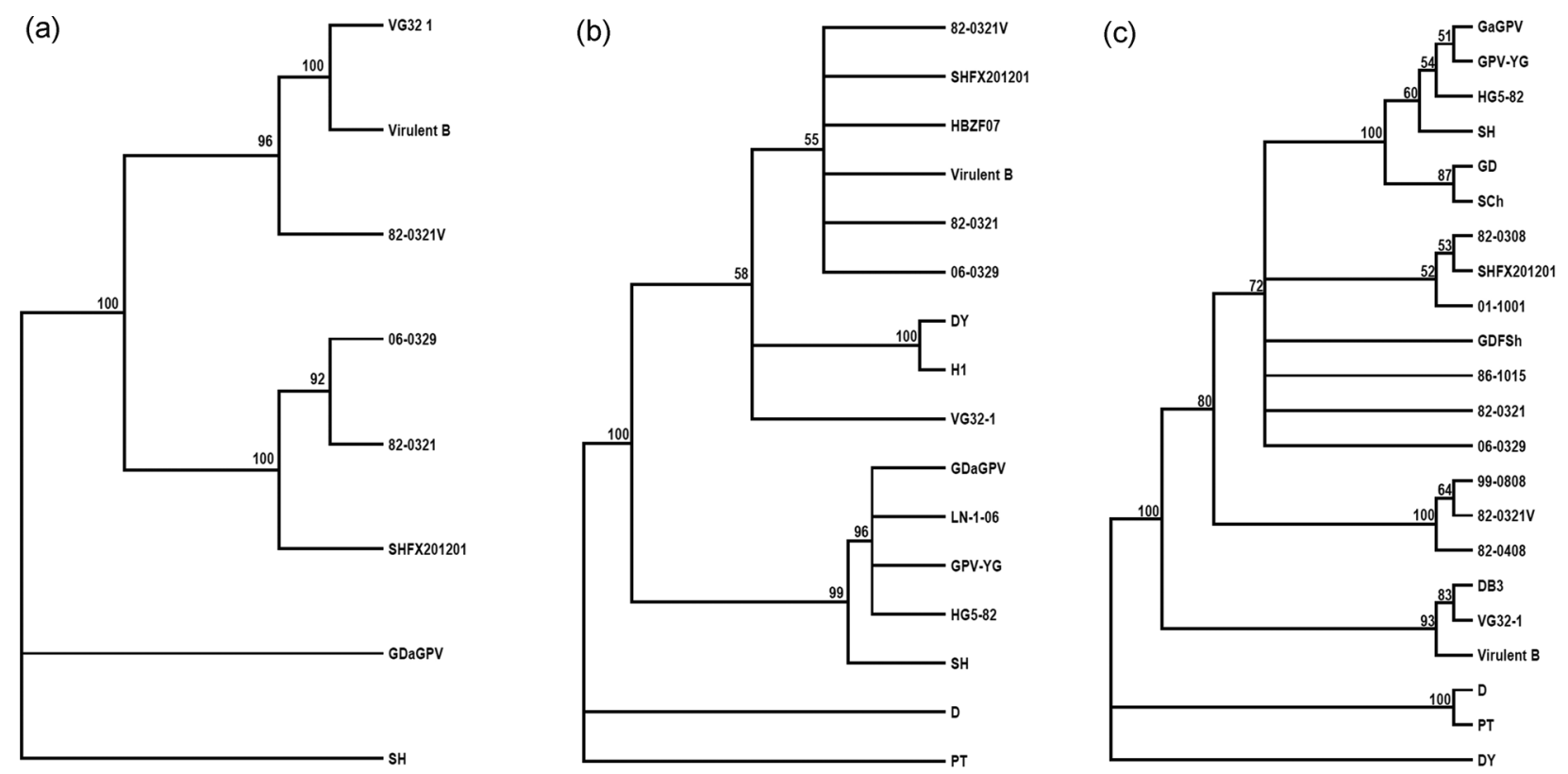

Fig. 3

Phylogenetic trees of GPVs

The trees were based on nucleotide sequence of complete genome (a), deduced amino acid sequences of NS (b), and VP1 (c), respectively.

fluid from the inoculated eggs was harvested and heated at $90^{\circ} \mathrm{C}$. After $10 \mathrm{~min}$ of heat treatment, the egg allantoic fluid was treated with Proteinase $\mathrm{K}(20 \mathrm{mg} / \mathrm{ml})$ at $56^{\circ} \mathrm{C}$ for 40 $\min$. Then, the equal volume of phenol and chloroform was used to extract the Proteinase K digested egg allantoic fluid and this procedure was repeated once more. The DNA in the supernatant was precipitated using 70\% ethanol, dissolved in sterile water and kept at $-20^{\circ} \mathrm{C}$ until use.

$P C R$. For screening GPV positive egg allantoic fluid, two primers GPV1 (5'-GCA GGA ACA ATT ACC AG-3') and GPV2 (5'-ACC ACC TCC CGC ACT GAC-3') covering a 776 bp fragment of the VP1 gene were used (designated as PCR I). Twenty-five $\mu \mathrm{l}$ PCR I amplification mixture contained water, 10x buffer, $2.5 \mathrm{mmol} / \mathrm{l} \mathrm{MgCl}_{2}, 2.5 \mathrm{mmol} / \mathrm{l} \mathrm{dNTP}, 10 \mathrm{pmol}$ primers, $0.5 \mu \mathrm{l}$ of template DNA and $0.25 \mu \mathrm{l}$ of Taq DNA polymerase (Fermentas, China). The parameters of the PCR were as follows: one cycle of $95^{\circ} \mathrm{C}$ for $5 \mathrm{~min}$, followed by 30 cycles of $94^{\circ} \mathrm{C}$ for $1 \mathrm{~min}, 50^{\circ} \mathrm{C}$ for $1 \mathrm{~min}$ and $72^{\circ} \mathrm{C}$ for $2 \mathrm{~min}$, and then one cycle of $72^{\circ} \mathrm{C}$ for $10 \mathrm{~min}$. For sequencing the whole genome of the GPV, three primes P1 (5' - TT CAG CTG CTC ATT GGA GGG TT-3'), P2 (5'-TT CTCGAG GCG TGG TCA ACC TAA CA-3') and P3 (5'-GCA TGC CGC GCG GTC AGC CCA ATA-3') were synthesized according to Shien (Shien et al., 2008). $\mathrm{P} 1$ and $\mathrm{P} 2$ primers annealing to the ends of the whole genome amplified the two inverse identical $203 \mathrm{bp}$ fragments (designated as PCR II) (Shien et al., 2008). P3 primer located in nt position 198 to 221 and 4,885 to 4,908, amplified a 4,711 bp fragment (designated as PCR III) (Shien et al., 2008). Fifty $\mu \mathrm{l}$ PCR II or PCR III mixtures contained water, 10x buffer, 2.5 $\mathrm{mmol} / \mathrm{l} \mathrm{dNTP}, 25 \mathrm{pmol}$ primers, $2 \mu \mathrm{l}$ of template DNA and 0.5 $\mu$ of LA Taq DNA polymerase (TaKaRa Biotechnology Co., Ltd., China). The parameters of the PCR II or PCR III were described as follows: one cycle of $94^{\circ} \mathrm{C}$ for $1 \mathrm{~min}$, followed by 30 cycles of $94^{\circ} \mathrm{C}$ for $15 \mathrm{sec}, 57^{\circ} \mathrm{C}$ for $30 \mathrm{sec}$ and $68^{\circ} \mathrm{C}$ for $30 \mathrm{sec}$ (for PCR II) or for $5 \mathrm{~min}$ (for PCR III), and then one cycle of $68^{\circ} \mathrm{C}$ for $5 \mathrm{~min}$. All the PCR products were separated by $1 \%$ PAGE gel.

Sequencing. After separation by 1\% PAGE gel, the PCR II and PCR III products were cut and directly sent for sequencing by using an ABI 3730 Sanger-based genetic analyzer (Shanghai, China). The DNA sequences were assembled using SeqMan (DNAStar).

Sequence phylogenetic analyses. The sequences were aligned using Muscle Version 3.8.31. The bootstrap 50\% majority-rule consensus trees were constructed using the neighbor-joining method (1000 replicates) with the software Paup4.0.

\section{Results and Discussion}

All of the goose embryonated eggs inoculated with the tissue of the sick swan died within three days post inoculation. The virus recovered from the inoculated allantoic fluid was designated as SHFX1201. SHFX1201 did not show any 
hemagglutination to chicken red blood cells and was identified as GPV by PCR using two GPV specific primers, GPV1 and GPV2. As described in Fig.1a, a GPV specific gene fragment with size of about $776 \mathrm{bp}$ was amplified from the allantoic fluid of the eggs inoculated with liver and intestinal tissue of the swan. No DNA fragment was amplified from the control allantoic fluid. The specificity of the 776 bp gene fragment of GPV was further confirmed by sequencing. To further study the genome characteristics of the isolate, the whole genome was amplified using primers P1, P2 and P3 as described in Materials and Methods. As shown in Fig.1b and $\mathrm{c}$, the size of PCR product amplified by primer P1 and P2 was about 200 bp in length, and that amplified by P3 was about $4,700 \mathrm{bp}$. These PCR products were directly sequenced, and the whole genome of the swan isolate was assembled using SeqMan (DNAStar) and submitted to GenBank (Acc. No. KC478066).

The sequence data revealed that the whole genome of the swan isolate was 5,050 nt in length. The swan isolate nt size was shorter than that of the two reported Chinese mainland isolates $\mathrm{SH}$ and GDaGPV both carrying 5,106 nt. However, the genome size of the swan isolate was exactly the same as the Taiwanese isolate 82-0321 isolated in 1982. In comparison with isolate $\mathrm{SH}$ and GDaGPV, two deleted sequences at nt positions $67-80$ and $334-347$ in ITR were found in the genome of the swan isolate as shown in Fig.2. Of note, the ITR of the swan isolate showed $100 \%$ identity with that of 82-0321 isolate. Although the nt deletions in ITR were observed also in other GPV isolates (Shien et al., 2008), we found that the nt deletion regions were mainly related to the sequences "TCCGGT" and "ACCGGA" as indicated in Fig.2 with red and purple squares respectively. These short sequences might serve as cis-regulatory elements, however, little is known about the role of these nt deletions or short repeats of complementary sequences in gene transcription and viral replication for GPV.

In addition to ITR, the coding regions also showed the highest homology to the Taiwanese isolates isolated in 1982. The NS protein of the swan isolate had $99.8 \%$ identity to that of Taiwanese isolate 82-0321. The NS of the swan isolate had only one mutation at position $28(\mathrm{H} 28 \mathrm{D})$ when compared with the NS of 82-0321. 28D was located in NS protein catalytic like domain and highly conserved in 14 of 15 isolates reported. However, the function of $28 \mathrm{D}$ in viral replication needs further elucidation. For VP1 protein, the swan isolate also showed high identity to both Taiwanese isolates (100\% to $82-0308$ and $99.7 \%$ to $82-0321$ ), but the identity to the Chinese mainland isolates was from $92.1 \%$ to $98.1 \%$. When compared with isolate 82-0321, the swan isolate had two mutations $\mathrm{P} 485 \mathrm{~T}$ and K523E in VP1. Since positions 485 and 523 are near to the two potential receptor binding sites (Opie et al., 2003; Shien et al., 2008), P485T and K523E mutations might be involved in the virus receptor binding and host tropism. Phylogenetic analysis also showed that the VP1 of the swan isolate and the other Chinese mainland isolates were clustered into the different groups as described in Fig. $3 c$, possibly indicating that multiple serological types of GPV might exist in mainland China. The high homology of the genome of the swan and Taiwan isolate of 1982 suggests the swan isolate might be derived from the 1982 Taiwanese isolates (Fig. 3a, b and c).

In conclusion, a GPV isolate, named SHFX1201, was isolated from the swan in Shanghai, China. To our knowledge, this is the first demonstration of the isolation of GPV from the swan. The 5,050 nt of the whole genome of the swan isolate also indicates at least two GPV genotypes (5,050 nt and 5,106 nt), that might exist in mainland China. Both non-coding and coding sequences of the swan isolate showed highest homology to the 1982 Taiwanese isolates, indicating that the swan isolate might be derived from Taiwanese isolates. These findings provide insights for investigating the molecular characteristics and etiology of GPV. However, the pathogenesis, host range and epidemiology of the swan isolate requires further investigation.

Acknowledgements. The authors thank Sherry Blackmon and Ashok Kumar Chockalingam for their proofreading and helpful comments. This study was supported by the Program for Changjiang Scholars and Innovative Research Team in University (IRT0978), the Priority Academic Program Development of Jiangsu Higher Education Institutions and Chinese Special Fund for Agroscientific Research in the Public Interest (201003012).

\section{References}

Brown KE, Green SW, Young NS (1995): Goose parvovirus--an autonomous member of the dependovirus genus? Virology 210, 283-291. http://dx.doi.org/10.1006/viro.1995.1345

Derzsy D, Dren C, Szedo M, Surjan J, Toth B, Iro E (1970): Viral disease of goslings. 3. Isolation, properties and antigenic pattern of the virus strains. Acta Vet. Acad. Sci. Hung. 20, 419-428.

Fang D (1962): Recommendation of GPV. Veterinary Science in China, 19-20 (in Chinese).

Gough D, Ceeraz V, Cox B, Palya V, Mato T (2005): Isolation and identification of goose parvovirus in the UK. Vet. Re.c $156,424$.

Irvine R, Ceeraz V, Cox B, Twomey F, Young S, Bradshaw J, Featherstone C, Holmes J P, Ainsworth H, Jones R (2008): Goose parvovirus in Great Britain. Vet. Rec. 163, 461. http:// dx.doi.org/10.1136/vr.163.15.461

Jansson DS, Feinstein R, Kardi V, Mato T, Palya V (2007): Epidemiologic investigation of an outbreak of goose parvovirus infection in Sweden. Avian Dis. 51, 609-613. http://dx.doi.org/10.1637/0005-2086(2007)51[609:EIOAOO]2.0.CO;2

Lu YS, Lin DF, Lee YL, Liao YK, Tsai HJ (1993): Infectious bill atrophy syndrome caused by parvovirus in a co-outbreak 
with duck viral hepatitis in ducklings in Taiwan. Avian Dis. 37, 591-596. http://dx.doi.org/10.2307/1591694

Opie SR, Warrington KH Jr, Agbandje-McKenna M, Zolotukhin S, Muzyczka N (2003): Identification of amino acid residues in the capsid proteins of adeno-associated virus type 2 that contribute to heparan sulfate proteoglycan binding. J. Virol. 77, 6995-7006. http://dx.doi.org/10.1128/ JVI.77.12.6995-7006.2003

Schettler CH (1971): Isolation of a highly pathogenic virus from geese with hepatitis. Avian Dis. 15, 323-325. http://dx.doi. org/10.2307/1588703

Shien JH, Wang YS, Chen CH, Shieh HK, Hu CC, Chang PC (2008): Identification of sequence changes in live attenuated goose parvovirus vaccine strains developed in Asia and Europe. Avian Pathol. 37, 499-505. http://dx.doi. org/10.1080/03079450802356979

Sirivan P, Obayashi M, Nakamura M, Tantaswasdi U, Takehara K (1998): Detection of goose and Muscovy duck parvoviruses using polymerase chain reaction-restriction enzyme fragment length polymorphism analysis. Avian Dis. 42, 133-139. http://dx.doi.org/10.2307/1592585

Takehara K, Nishio T, Hayashi Y, Kanda J, Sasaki M, Abe N, Hiraizumi M, Saito S, Yamada T, Haritani M, et al (1995): An outbreak of goose parvovirus infection in Japan. J. Vet. Med. Sci. 57, 777-779. http://dx.doi.org/10.1292/jvms.57.777

Wan C H, Zhu HX, HuangY, Peng CX, Cheng LF, Shi SH (2011): Genomic characterizations of a parvovirus isolated from goose. Chin. J. Anim. Infect. Dis. 19, 19-24.

Wozniakowski G, KozdrunW, Samorek-Salamonowicz E (2009): Genetic variance of Derzsy's disease strains isolated in Poland. J. Mol. Genet. Med. 3, 210-216. http://dx.doi. org/10.4172/1747-0862.1000037

Zadori Z, Stefancsik R, Rauch T, Kisary J (1995): Analysis of the complete nucleotide sequences of goose and muscovy duck parvoviruses indicates common ancestral origin with adeno-associated virus 2. Virology 212, 562-573. http://dx.doi.org/10.1006/viro.1995.1514 